\title{
The digital transformation of management consulting companies: a qualitative comparative analysis of Romanian industry
}

\section{Emil Lucian Crișan ${ }^{1}$ (D) Liana Stanca ${ }^{1}$}

Received: 7 January 2021 / Revised: 15 June 2021 / Accepted: 8 July 2021 /

Published online: 27 July 2021

(c) The Author(s), under exclusive licence to Springer-Verlag GmbH Germany, part of Springer Nature 2021, corrected publication 2023

\begin{abstract}
Digital transformation affects all industries. This study targets how management consulting companies address this phenomenon. Based on a survey of 30 Romanian management consulting companies and a qualitative comparative analysis, we model the relationship between management consulting companies' current context (customers' industries, internal and external triggers for digital transformation), the current state of digital transformation, and expected digital transformation. By considering managerial expectations importance in future decisions, and contingency theory for explaining the links between context, current state and expected digital transformation, different paths concerning digital transformation are identified at Romanian management consulting companies. For some of them, the combination of internal and external triggers and the existence of previous digital transformation activities led to increases in the recognized importance of digital transformation in future business models and to newer business services (digital strategy). For others, which do not have powerful external triggers, digital transformation is associated with internal efficiency-related triggers, and it targets only improvements in existing business models due to technology adoption (technology strategy). A small number of management consulting companies do not expect digital transformation to have a large impact on their future business model, because of either the lack of external triggers to do so or the absence of previous digital transformation activities. This research demonstrates the contingency and evolutionary nature of the digital transformation process, in which specific combinations between internal and external triggers can explain the expectations of management consulting companies' managers about digital transformation.
\end{abstract}

Emil Lucian Crișan

emil.crisan@econ.ubbcluj.ro

1 Faculty of Economics and Business Administration, Babes-Bolyai University, Cluj, Romania 
Keywords Digital transformation - Management consulting companies - Managerial expectations · Digitalization - Qualitative comparative analysis · Contingency theory

\section{Introduction}

One major phenomenon faced by all businesses these days is digital transformation, "a fundamental change process, enabled by the innovative use of digital technologies accompanied by the strategic leverage of key resources and capabilities, aiming to radically improve an entity and redefine its value proposition for its stakeholders" (Gong and Ribiere 2020, p.12). Although digital transformation has been analyzed in different contexts and many papers offer holistic perspectives on this topic (e.g., Hausberg et al. 2019; Hanelt et al. 2020), several questions remain about how digital transformation is performed in specific industries, what leads companies to move from the adoption of simple information technology to digital transformation, and how they are interconnected. These research questions remain unanswered because recent papers provide only general insights about the phases of digital transformation (i.e., Verhoef et al. 2021), and the theoretical debate over the phenomenon is still open, as shown by the numerous recent reviews on the field (Hausberg et al. 2019; Vial 2019; Hanelt et al. 2020).

Considering these research gaps, this paper investigates digital transformation of one knowledge-based service industry, management consulting. This sector is one of the largest and most mature markets in professional industrial services, the value of global management consulting has increased from US $\$ 107$ billion in 2011 to US\$160 billion in 2019 (Mazareanu 2020). This maturity, and the critical role played by management consulting in the management of innovation of business and public organizations (Cerruti et al. 2019), has not been accompanied by significant academic research interest (Bronnenmayer et al. 2016). This paper builds on earlier work concerning service industries, which mainly suggests that management consulting companies should have important advancements concerning digital transformation in comparison to final customer-oriented businesses (Wallin and Fuglsang 2017). It also builds on the literature concerning management consulting digital transformation, in terms of the descriptive statistics and case studies previously used to analyze distance consulting in Italy (Allegra et al. 2000), the democratization of management consulting due to digitization in more advanced countries (Llewellyn 2017), and digital transformation of German management consulting market (Nissen and Seifert 2018; Nissen et al. 2019). Although management consulting companies are important technology providers and enablers of change for their customers (Christensen et al. 2013; Cerruti et al. 2019), the challenges faced by these companies and how these companies are affected by this global phenomenon have received little analysis in the existing research (Nissen 2018). We analyze in this paper a less developed management consulting market, the Romanian one. Because Romania has had a market economy for only 30 years, its management consulting market is still considered rather new; its initial development was due to the opening of local offices by Western 
companies (Gross et al. 2004), but lately the IT industry is leading changes in the economic ecosystem (Fan et al. 2019). To date, no papers have analyzed the digitization practices of Romanian management consulting companies, but the current analysis contributes to the existing research on the evolution of Romanian companies toward the so-called fourth industrial revolution, or industry 4.0 (Türkeş et al. 2019). Because Romanian companies are willing to adopt digital transformation but lack understanding of its strategic importance (Türkeș et al. 2019), our study offers insights into management consulting companies' recognition of this strategic opportunity.

In this context, this paper poses the question:

How do Romanian management consulting companies get involved in digital transformation: Do they consider potential triggers for particular digital transformation approaches, their state of digital transformation, or expectations concerning the future impact of digital transformation on their business models?

To observe digital transformation in management consulting, we construct a model of the evolutionary nature of the phenomenon based on contingency theory (Van de Ven et al. 2013) which considers that current and future digital transformation choices are made by considering internal and external context, and the dual role played by managerial expectations. They are described as both the results of previous digital transformation activities and factors in future actions (Dacin et al. 2002; Li et al. 2018). The proposed model has three dimensions: the context, the current state, and the expected state of digital transformation. This model is used in a qualitative comparative analysis (QCA) to identify the different pathways followed by Romanian management consulting companies in their digital transformation process. The data was gathered from a survey conducted among representatives of Romanian management consulting companies. Through the use of QCA, we identified multiple paths to digital transformation, and each consists of the context, the current state of digital transformation, and the expected state of digital transformation, which describe organizations' current digital transformation path. This path refers to the past (previous results and context) as well as the future (expectations are considered antecedents of future), which captures management consulting companies' involvement in the digital transformation process. Given the size of the sample (30 companies) and the characteristics of the theoretical model, we adopted QCA for this analysis (Schneider and Wagemann 2012). In this case QCA demonstrates its effectiveness by explaining how different combinations of external triggers and the current state of digital transformation are associated with similar outcomes, in particular managers' expectations about digital transformation.

The paper is structured as follows: Sect. 2 reviews the literature on digital transformation in general and how it has been analyzed by services and management consulting researchers and proposes our model. Section 3 details the methodology used, containing the data and sample, the variables, and the analysis. In Sect. 4 the results are detailed, Sect. 5 presents the discussion, and Sect. 6 concludes. 


\section{Literature review}

\subsection{Digital transformation in services and management consulting}

The research concerning information technology use in business was initially dominated by the technology adoption paradigm, which could be considered as preceding digital transformation. Digital transformation is a new paradigm that looks at the organizational side and considers how organizations change with the use of technology to increase the value that they create for their customers (Chanias et al. 2019; Hanelt et al. 2020). Considering the digital transformation paradigm, technology adoption is only one piece of the puzzle for organizations as they try to remain competitive (Vial 2019). Digital transformation is "a process that aims to improve an entity by triggering significant changes to its properties through combinations of information, computing, communication, and connectivity technologies" (Vial 2019, 118) and leads to major changes in business processes, operational routines, organizational capabilities, and even the markets for the business ( $\mathrm{Li}$ et al. 2018). Digital transformation can affect customer value propositions, the operating model, or a combination of both, depending on the industry (Berman 2012). Another interpretation is that digital transformation can be used for innovation, integration, or both, emphasizing that digital transformation does not only change how things are made (integration), but it can introduce novelty into the strategy and operations (innovation) (Hanelt et al. 2020). Three stages of digital transformation have been identified (Verhoef et al. 2021): digitization (converting analog information into a digital form), digitalization (improving existing processes using IT), and digital transformation (the transformation of business models using IT).

In service industries, digital transformation has been generally recognized as capable of influencing and determining changes in adopters' business models, overcoming traditional constraints, accelerating delivery of services, and increasing the availability and efficiency of services (Laudien and Pesch 2019). Digital transformation for predigital organizations is recognized as an iterative process that depends on the external and internal context, and the latter is in continuous evolution because previous digital transformation results are inputs for future actions (Chanias et al. 2019). Changes are not visible in all service industries, and more digital transformation advancements are observed in business-to-business services (Laudien and Pesch 2019) in comparison to final customer-oriented businesses (Wallin and Fuglsang 2017). Four digital transformation trajectories are considered for service businesses (Zaki 2019): digital technology (the wide use of digital technologies, such as mobile, virtual reality, artificial intelligence, business process automation, and the internet of things for performing existing services-also called IT-enabled transformation), digital strategy (unlike IT-enabled transformation, it is related to the organizational changes associated with redefining the business scope, embedding technology in new services, and creating new value propositions in general), customer experience (major focus on understanding customer experience by using sophisticated analytical tools), and 
data-driven business model (effective data utilization to improve existing business models). Most service businesses only adopt IT, which targets improvement in their traditional activities, instead of radical changes in their business models (Laudien and Pesch 2019).

In the management consulting industry, the digital transformation level is surprisingly low (Greff and Werth 2016), which is hard to explain considering that management consulting companies are recognized for their evangelist role in their customers' business transformation (Llewellyn 2017). The research on management consulting companies digital transformation is also at an incipient phase (Seifert and Nissen 2018), and the existing research investigates a few narrow topics, such as the forms of the adopted IT and how they affect the nature of consulting (Deelmann 2018). Research in the management consulting field in general lags development of the industry (Mosonyi et al. 2020). One approach to studying digital transformation in management consulting is to propose models, frameworks, and concepts, which describe the conditions faced by the consulting industry and to present evidence in the form of examples or case studies of these models. Christensen et al. (2013) show that management consulting is currently in a disruption phase, in which the early signs include new customer demand for the use of new technologies such as automation and the use of databases and the blurring of boundaries between professional services. Similarly, Deelmann (2018) offer evidence that digitization (which is used by the author as a synonym for digitalization) affects the market by influencing management consulting companies' efficiency and their business models, including automation of consulting services. Llewellyn (2017) demonstrates that digitalization has "democratized" consulting by introducing new consulting models (i.e., digital associate-based consulting, which allows customers to handpick consultants from a digital pool, or peer-to-peer online consulting). Nissen et al., in various papers (Nissen and Seifert 2015, 2018; Nissen et al. 2019), use descriptive statistics to analyze digital transformation in management consulting. An analysis of the impact of virtualization of the client-consultant relationships, through a Delphi study, shows the equivocal expected impact of this approach: the positive effects are improved effectiveness and flexibility, and the negative effects are weaker client-consultant relationships (Nissen and Seifert 2015). Later, digital transformation in the consulting industry is presented as both a driver and a result of changes in all industries due to the evolution of technologies such as cloud computing and big data (Nissen 2018). Another important contribution is an analysis of the German management consulting market and its adoption of different digital technologies (Nissen and Seifert 2018; Nissen et al. 2019), which details the forms adopted by consulting firms as well as their future intentions. The adoption of digital tehcnologies is seen as a trigger for new entrants to create new business models, such as for old providers to adapt existing models. Few papers use advanced empirical methodologies to investigate the digital transformation of the management consulting industry. By considering the state of the current research concerning management consulting, this paper builds on the work mentioned above by Nissen et al. (Nissen and Seifert 2015, 2018; Nissen et al. 2019) by using QCA to observe the digital transformation of Romanian management consulting companies. 


\subsection{A theoretical model for analyzing digital transformation}

The main points of departure for our theoretical model are existing theoretical frameworks on the evolutionary nature of digital transformation and those on managerial expectations, which highlight them as both outcomes of different organizational antecedents and determinants of newer technology adoption efforts. Based on these theories, we construct a model that considers three dimensions (digital transformation context, current state of digital transformation, and digital transformation expectations).

\subsubsection{The evolutionary nature of digital transformation}

Digital transformation is recognized as an ongoing process (Chanias et al. 2019), in which companies that design digital transformation strategies discover new ways to improve their activities after they take steps toward digitalization. Companies need to accept the need to adopt malleable organizational designs, which are embedded in and driven by digital ecosystems, because all partners involved in value creation and capture need to align their actions (Hanelt et al. 2020). This continuous internal changes triggered by external factors are best described by contingency theory, which holds that the external context and organizational structure must somehow fit together if the organization is to perform well (Drazin and Van de Ven 1985). Though it has been initially developed for more static environments, it is recognized as capable to explain the complex reality which characterizes current organizations (Van de Ven et al. 2013). In the case of digital transformation this reality is described by continuous episodes of recursive and adaptation activities, with a targeted result, rather a "moving target" (Chanias et al. 2019). By adopting this dynamic view of contingency theory (Van de Ven et al. 2013), it could be considered that the context (including both external contingencies and internal capabilities, which we believe also include managerial cognition) influences the structure or the strategies, which become later the partial context (other external and internal factors will be added) for future strategies.

\subsubsection{Managerial expectations}

The second theoretical framework we consider is that of management expectations. Different terms have been used to describe managers' perceptions about the future: "perceptions," "expectations," "sensemaking," and "vision." They mean approximately the same thing and refer to what managers think about the future, but "expectations" emphasize to a greater extent their enacting and normative character, "the wishful enactments of a desired future" (Borup et al. 2006). They are recognized as constitutive forces that guide technology developments and innovation, which vary over time, alternating between hype and disappointment, as they also vary across groups and space (Borup et al. 2006). Managerial expectations are social constructs, which represent how managers perceive reality, because organizations behave in 
accordance with their socially constructed reality (Wallin and Fuglsang 2017). In this way, management perceptions can be considered both an output of organizations and an input for future innovation processes.

\subsubsection{The model}

We propose a different perspective of digital transformation that encompasses its continuous nature and the role played by managers' expectations and show that management consulting companies, at a given moment, perform in a given context (internal and external), have taken some steps toward digital transformation, and have obtained some results related to their different expectations about future digital transformation. Every set (the current state of digital transformation-the expected digital transformation) describes the current path in organizations' digital transformation. This path is related to the past as well as to the future. By encompassing contingency theory (Drazin and Van de Ven, 1985; Van de Ven et al. 2013), the current state of digital transformation is the result of interaction between the context and the organization over time, whereas by including the constructivist nature of managerial expectations (Wallin and Fuglsang 2017), the current state and context of digital transformation are determinants of managerial expectations about digital transformation. These paths change over time because the intermediate results of digital transformation (state of and expectations about digital transformation) are further recombined with external and internal organizational stimuli to generate new rounds of digital strategy (Chanias et al. 2019). Based on this perspective, we design a model that links managerial expectations with management consulting companies' internal and external context and the current state of digital transformation, as shown in Fig. 1.

Concerning the first dimension in the model, the context, previous technology adoption models, such as technology-organization-environment framework proposed by Tornatzky et al. (1990), confirm that the adoption of technology is influenced
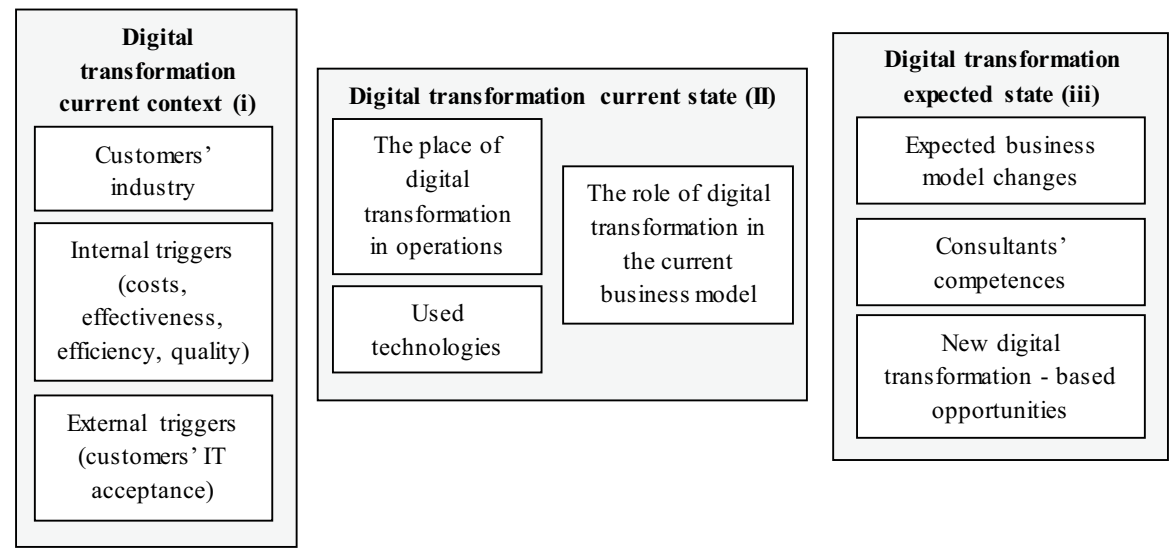

Fig. 1 Dimensions of the model 
by three contexts: technological, organizational, and environmental (Oliveira and Martins 2011). Our model differentiates between the internal and external context because digital transformation is driven by and embedded in the digital business ecosystem (Hanelt et al. 2020). These two aspects concerning the context in which digital technologies are adopted have been also considered in another framework which explains digital transformation by adopting an innovation diffusion perspective (Steiber et al. 2020). Our model has three variables for the context: management consulting companies customers' industry, internal triggers, and external triggers. The industry seems to be a very important factor because customers in different industries have different strategies for IT adoption and digital transformation. Strategies such as rapid IT adoption (Curuksu 2018), can determine whether management consulting companies have a rapid transformation or take slower approaches. These triggers are recognized as influencing the framing conditions of management consulting companies' clients, overall market development, and the consulting services model provided by management consulting companies (Deelmann 2018).

Three variables are used for the second dimension of the model, the current state of digital transformation: the current role played in the existing business model by IT, its role in companies' operations, and the technologies currently used by the companies. This comprises the use of digital technologies, and advanced digital transformation (business model). Business model theory (Ojala 2016; Schallmo et al. 2017; Li 2020) is used for both the second (current state of digital transformation) and third (expected digital transformation) dimensions. It motivates us to analyze these variables in relation to the dimensions of the main business model: products/services, value network, value delivery, and revenue model. Because the management consulting industry is recognized as a market in which the main drivers of competitiveness are not price and quality but, rather, trust, reputation, and social relations in general (Glückler and Armbrüster 2003), digital transformation is expected to have a smaller impact on management consulting companies' business models. The previous results identified by Nissen et al. (2019) for the German market suggest that management consulting companies' business models are primarily affected in value network terms since more and more consultants and clients work together locally separated. For creative industries, Li (2020) provides evidence that digital technologies are mainly used to enhance the current business models by facilitating communication with customers and stakeholders.

The third dimension consists of the transformations expected at management consulting companies due to the impact of digital transformation on the business consulting industry. One variable in this dimension measures the changes faced by management consultants and the importance of new and old competences. Some evidence shows that this transformation influences the content of the current requirements for being a consultant, as adoption of technology such as big data, data science, and internet of things, which are still in their infancy, is rather slow (Bensberg et al. 2019). The second variable measures expectations of changes in business models due to digital transformation. Many prior papers have described these changes (Christensen et al. 2013; Parakala 2015; Greff and Werth 2016; Deelmann 2018). Another variable describes potential services considered by management consulting companies to be launched in the future as digital technologies are recognized by 
literature to cause the increasing adoption of multiple business models rather than replacing the previous ones ( $\mathrm{Li} 2020)$.

\section{Methodology}

\subsection{Data and sample}

This study uses data from a survey conducted in December 2019-March 2020, whose respondents were representatives of Romanian management consulting companies. The dimensions depicted in Fig. 1 are operationalized following prior models in the literature, using a questionnaire on the German management consulting market previously used by Nissen et al. (2019), which analyzes the digital transformation with a major focus on virtualization, of an industry in a single market. However, our empirical analysis is different as our use of a QCA is more suitable to the smaller Romanian market and the theoretical model described earlier. The questionnaire was translated into Romanian and tested before it was distributed to the entire population. For an English translation of the survey (questions and items), see Table 1 . The questionnaire was sent by email to the sample, which comprises 223 management consulting companies, with 30 respondents representing the $30 \mathrm{com}$ panies that responded completely (the response rate was 13.45\%), and their answers are included in the final analysis. The Romanian Management Consultancies Association supported the distribution of the questionnaire to their management consulting companies' members.

\subsection{Variables}

For each variable, we use questions already tested by Nissen et al. (2019) in the German management consulting market (see Table 1).

Three questions are used for context: Q1 for the customers' industry, Q6 for internal triggers, and Q8 for external triggers. The internal triggers for digital transformation were designed by Nissen et al. (2019): improvement of business image, consulting projects' quality, reduction in the number of consultants working on projects, increase in the number of projects by companies. The external triggers of digital transformation measure the acceptance of IT by existing customers (Parakala 2015; Seifert and Nissen 2018; Nissen et al. 2019), these triggers have been grouped into two categories based on a cluster analysis of the results provided by the respondents (see Table 2).

To evaluate the current state of digital transformation, in our first question we explore how much IT is part of a company's business model in communicating with customers, running different projects, developing new services, and automating current services offered to customers. Another question covers the current use of IT into daily operations, and the last question assesses the use of different technologies by consulting companies ( see Q4, Q5, and Q7 in Table 1). The items in Q4 are related to how IT is used in the four components of a business model (Ojala 2016): 


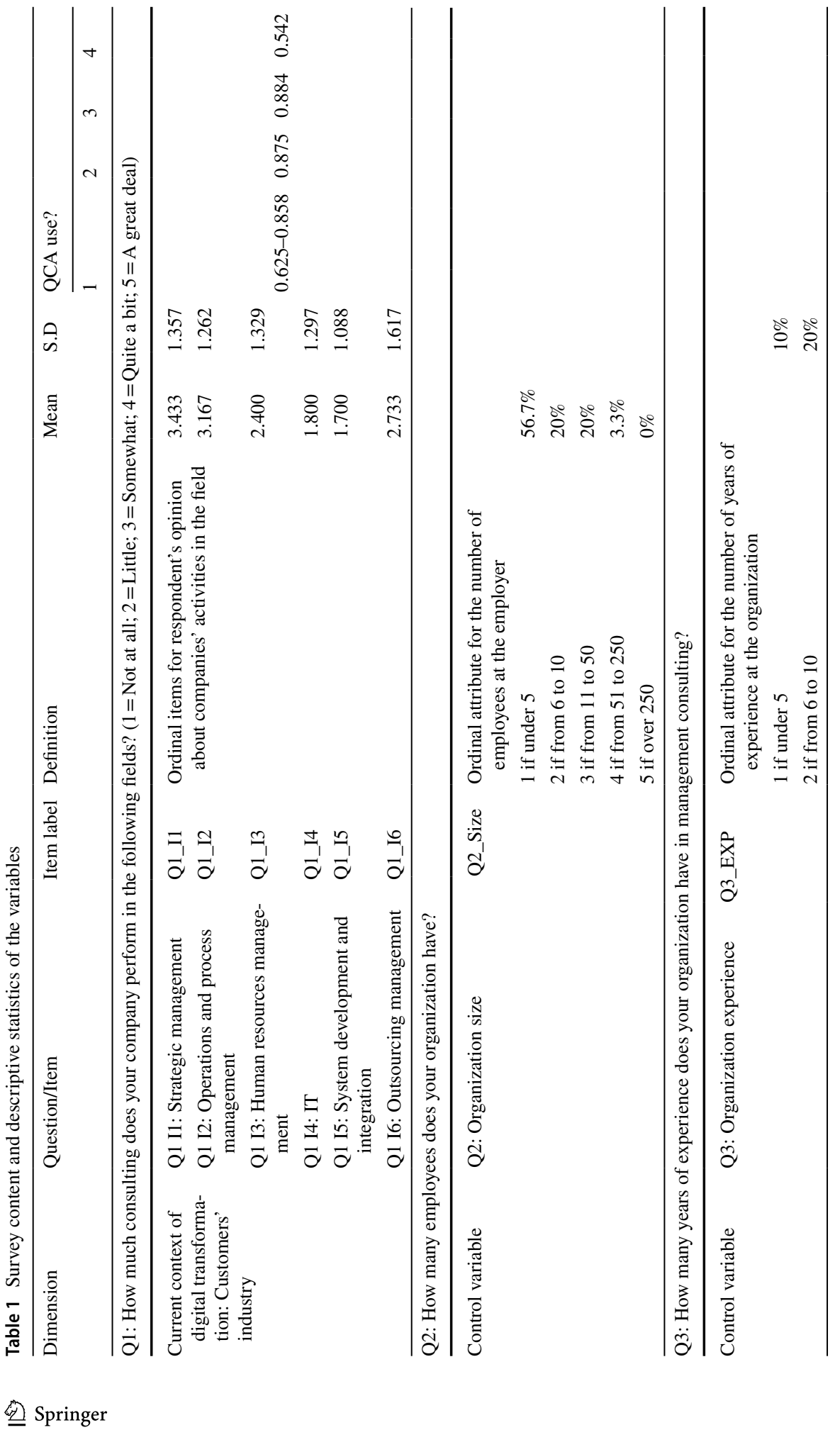




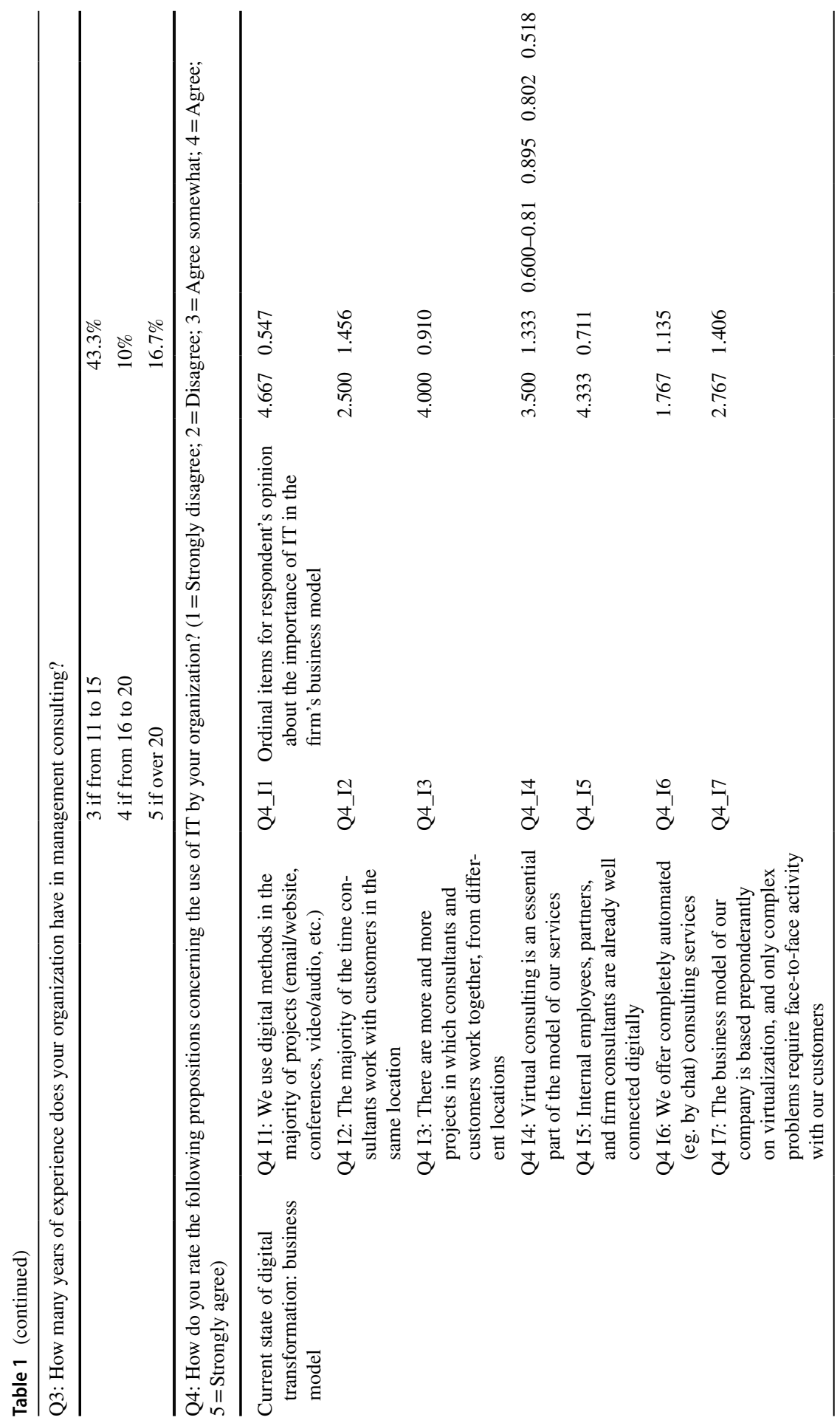




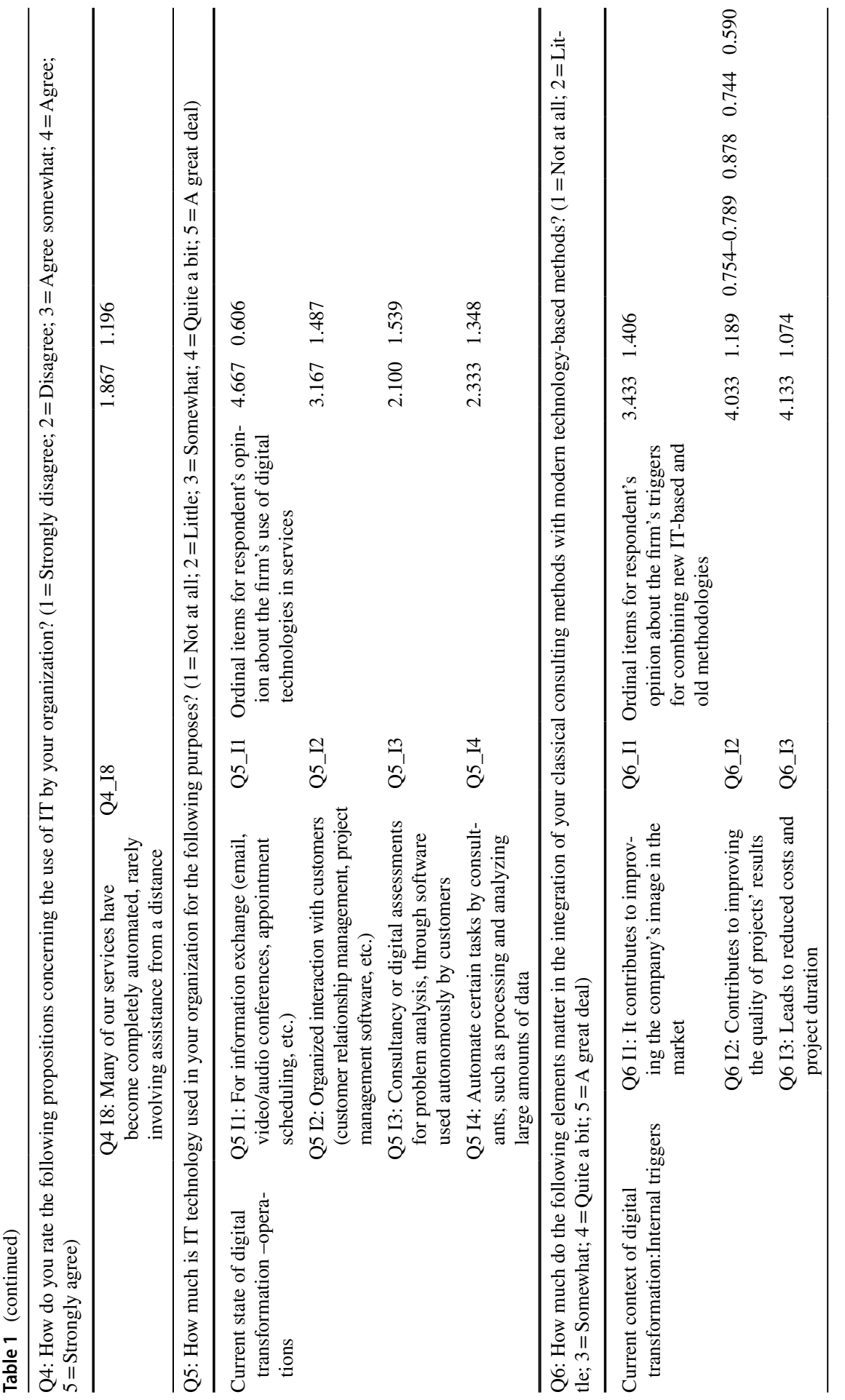




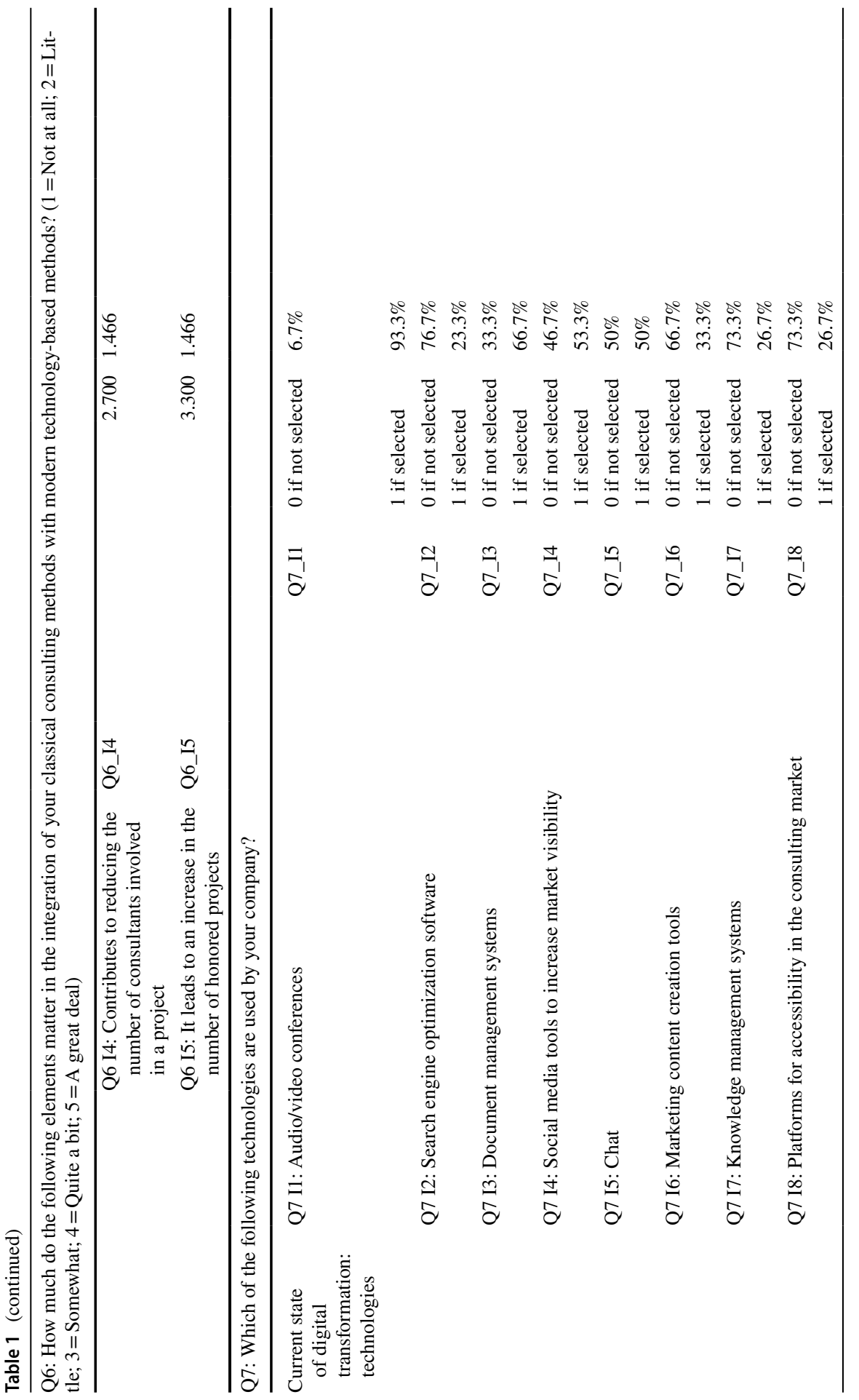


을 운

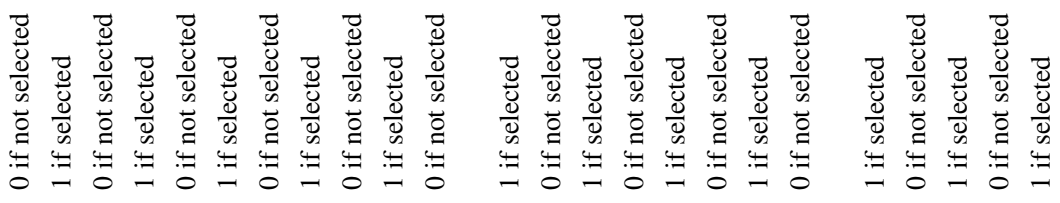

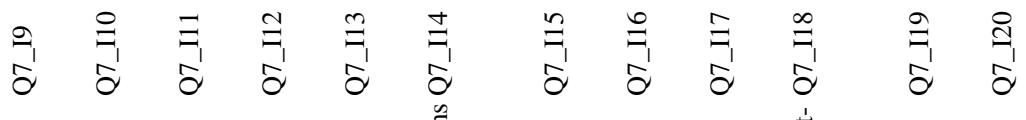

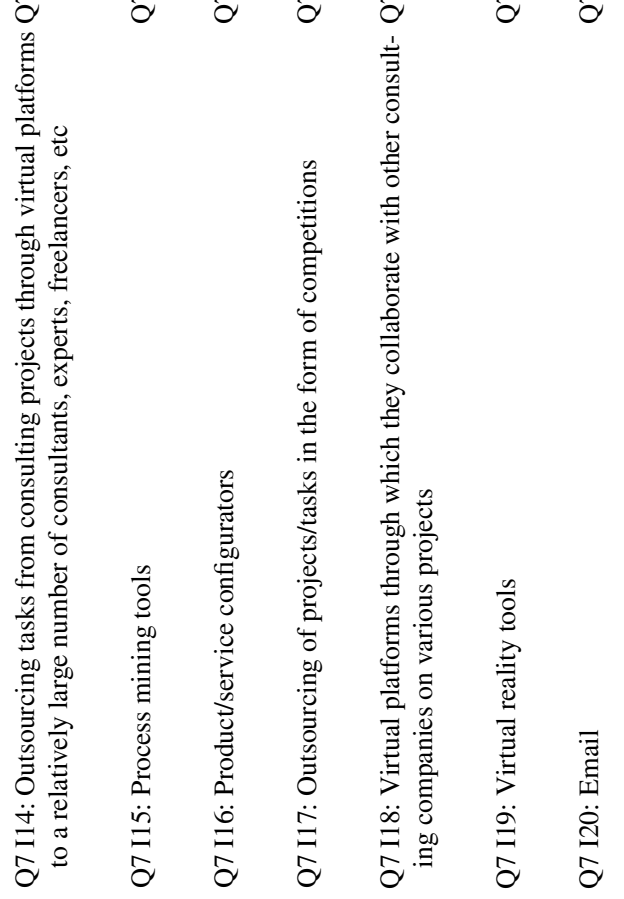




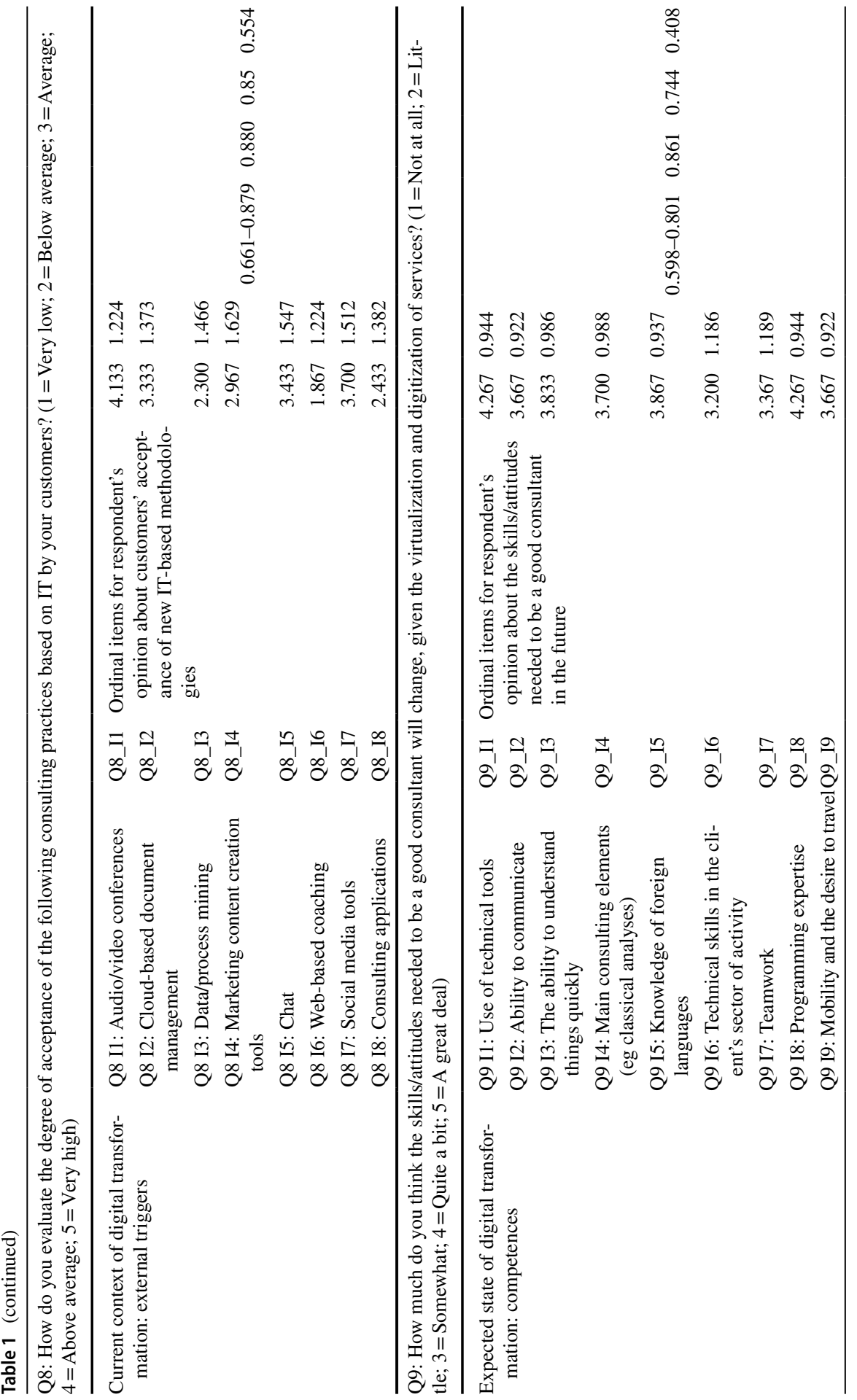




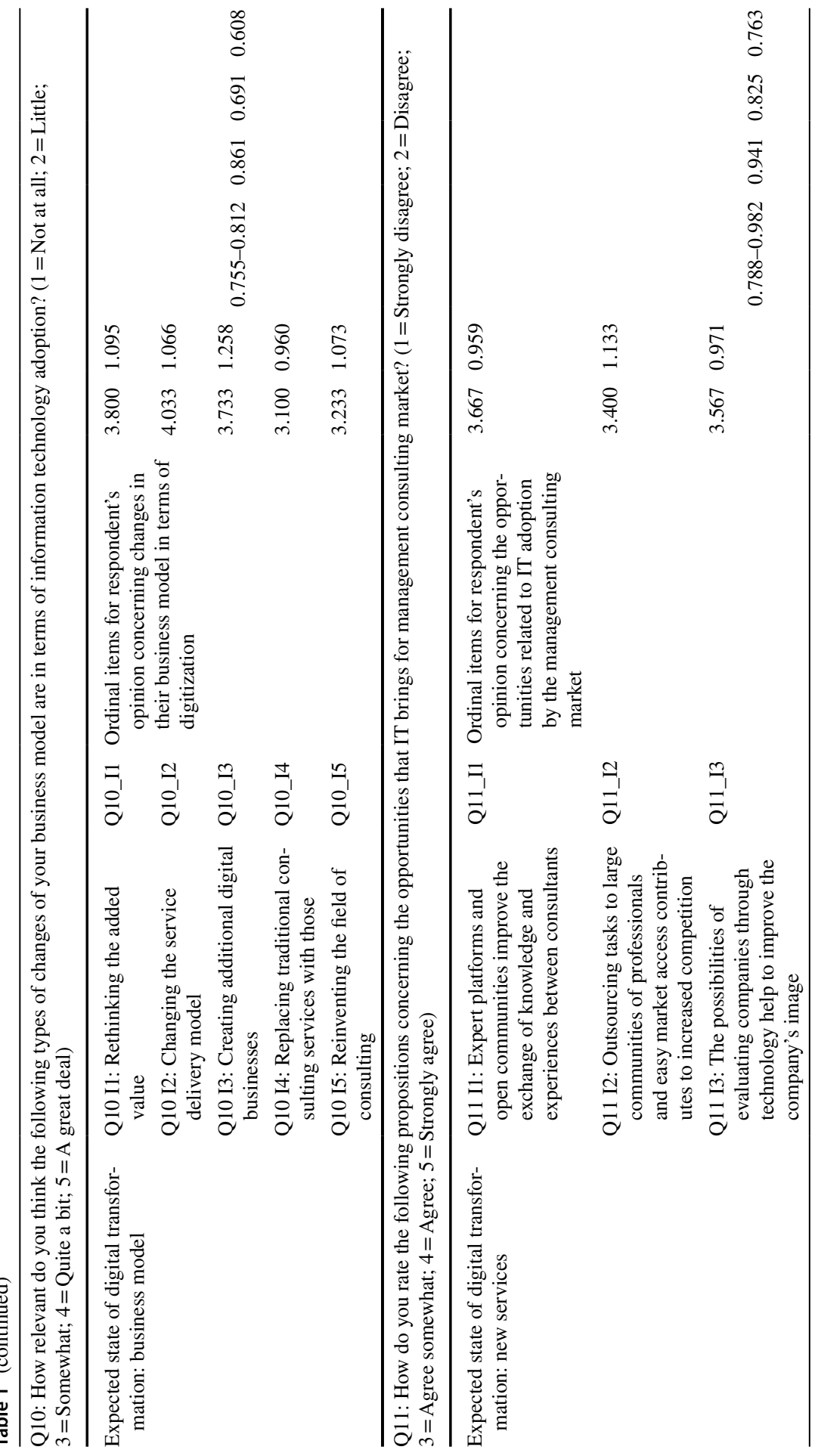




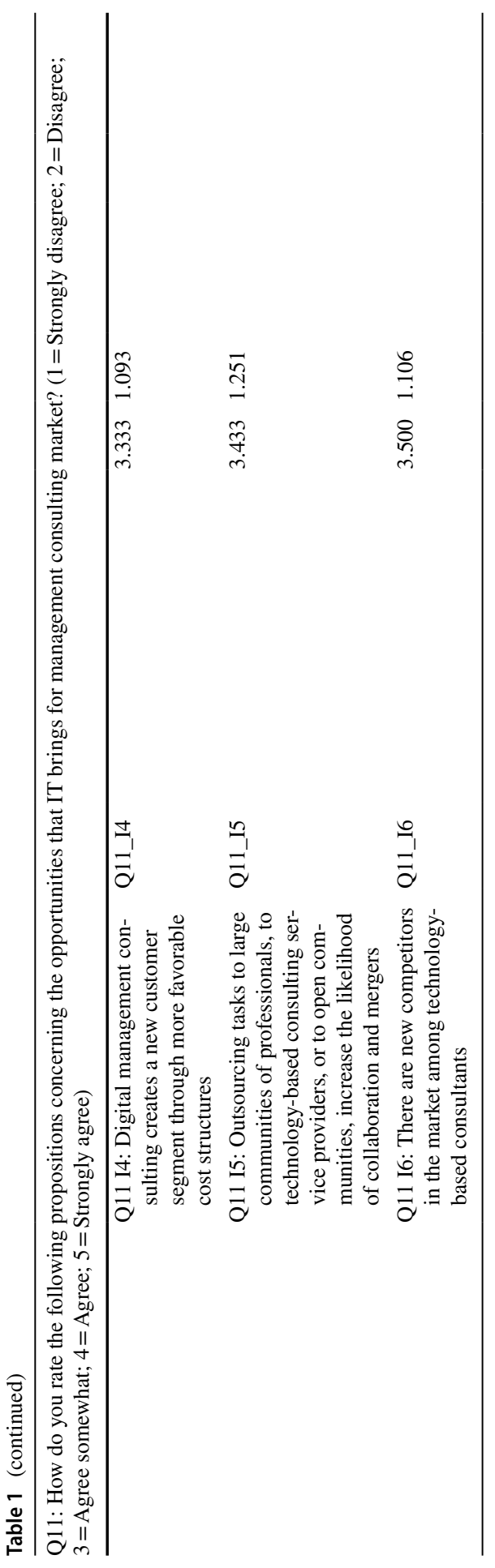




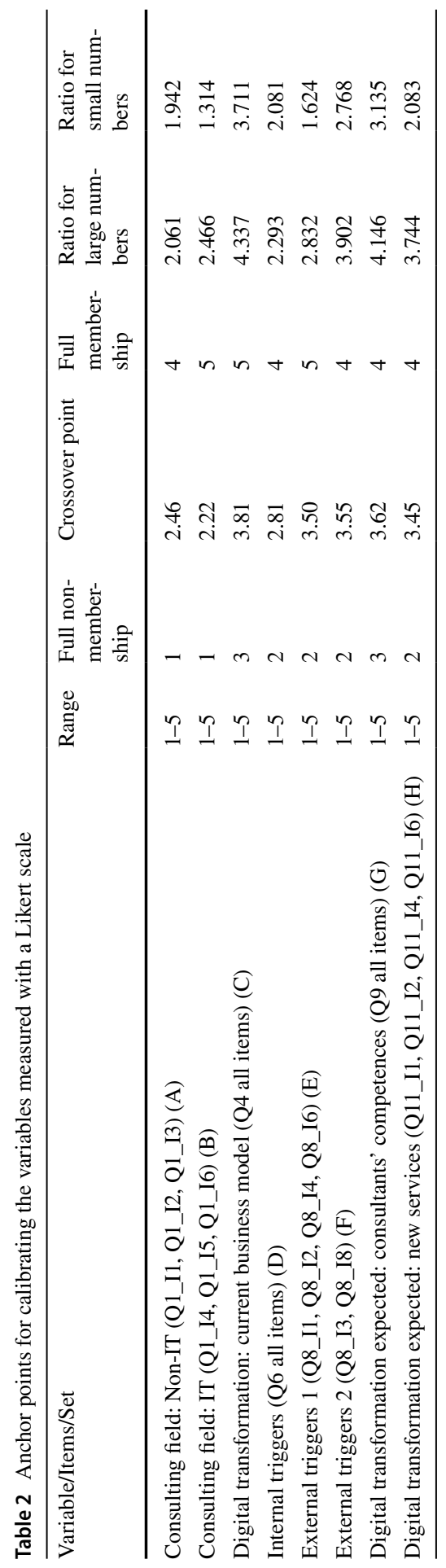


the product/service (the role of digital technologies in the services offered by companies: Q4_I1, Q4_I4), the value network (use of IT by stakeholders and partners: Q4_I5), value delivery (how IT is used in delivering services to customers: Q4_I2, Q4_I3, Q4_I7), and the revenue model (how IT is used in creating revenue for companies: Q4_I6, Q4_I8).

We used three questions on managers' expectations. The first one is about the changes faced by management consultants and the importance of new and old competences (Q9), the second is on the expectations for changes in companies' business models due to digital transformation (Q10), and the last examines potential services that will be important in the future (Q11). Two control variables are added. Q2 inquires about the size of the organization, and Q3 asks about MCC experience in the market. The size and experience of the companies are recognized as important variables for determining the different approaches employed by management consulting companies (Christensen et al. 2013; Nissen and Seifert 2018).

\subsection{Analysis}

Based on the theoretical model presented in Sect. 2, the nature of our research is exploratory. We determined that the QCA approach is suitable for our theoretical comparative-case analysis of the sample (Table 1). A comparative-case analysis often produces results that are compatible with different causal processes related to competing explanations of the outcome. Our study assesses "the empirical results based on actual theoretical knowledge," typical of the QCA approach (Schneider and Wagemann 2012). Causal complexity is guided by three principles: (1) conjunction refers to a result that arises from the interdependence of several conditions (Schneider and Wagemann 2012); (2) equifinality suggests the possibility of multiple pathways that lead to the same outcome (Gresov and Drazin 1997); and (3) asymmetry, which means that the characteristics are found to be causally related in a configuration that can be unrelated or even inversely related (Meyer et al. 1993).

According to the literature, QCA has three main variations: crisp set QCA (csQCA), multivalue QCA (mvQCA), and fuzzy-set QCA (fsQCA) (Ragin et al. 2009). The nature of the data involved, as well as the purpose of our research, led us to select fsQCA, as in other cases that employ the same methodology (Cooper and Glaesser 2012; Ragin 2014; Beynon et al. 2020; Yoruk and Jones 2020). Fuzzyset QCA is an advanced methodology for examining hypotheses and creating new theories (Yoruk and Jones 2020), which is useful for exploration of all the possible solutions that could explain the outcome of specific research or test specific relational models (Pappas 2018). Data analysis using fsQCA identifies all the possible combinations of independent variables, which might either be detected as outliers or not detected as such in typical variance-based approaches. Moreover, in fsQCA, sample representativeness does not affect the solutions (Fiss 2011), and its robustness is related to the fact that it is unaffected by previous values. These values can vary from very small ( $<50$ cases) to very large (thousands of cases) (Greckhamer et al. 2013). Fuzzy-set QCA can be applied to various types of data (Likert scales, click flux, multimodal data), which can be turned into fuzzy sets in the calibration 
stage, according to specific formulas (Ragin 2009). The fsQCA algorithm revolves around the idea of dividing the sample into various subsets, thus examining multiple combinations of conditions. In our case, fsQCA investigates how the outcome (expectations about future changes in management consulting companies' business model due to digital transformation; Question 10, Items Q10_I1-I4), are associated with input variables (management consulting companies' fields of activity, management consulting companies' internal and external triggers of digital transformation, the current state of digital transformation, and expectations about the evolution of management consultant competence and the development of new services).

The plan is to identify solutions and combinations of independent variables that lead to the outcome. It consists of several steps:

(1) Data calibration: transformation of the original data through the direct method by Ragin (2009), transforming variables into fuzzy sets (see Table 2). fsQCA is used to calibrate the output, facilitating the definition of "qualitative anchors" based on empirical data as follows: being "fully in" (1) a given set, being "neither in nor out" of a set (0.5), and being "fully out" (0) of a set (Ragin 2009).

(2) Simplification of multiple solutions: creating a truth table using the Eq. $2^{\mathrm{k}}$ lines/ rows, where $\mathrm{k}$ is the number of conditions, which each represents a specific configuration (Greckhamer et al. 2018). As the number of variables increases, the number of possible configurations increases exponentially $\left(2^{\mathrm{k}}\right)$; thus, the higher the number of variables, the more combinations that are likely to have a frequency of zero. This table of configurations that describe the data accurately (truth table) is presented in Table 3.

(3) Interpretation of results: evaluating the truth table to determine whether each combination (i.e., row in the table) explains the outcome. The solution refers to a combination of configurations that is supported by a high number of cases, where the rule "the combination leads to the outcome" is consistent (generally accepted absolute minimum 0.75 threshold; Ragin, Strand and Rubinson, 2008; Schneider and Wagemann 2012).

(4) In the final stage of the analysis, using Boolean logic, QCA searches for the simplest combinations of conditions that are still consistent with the outcome, through the minimization algorithm called Quine-McCluskey algorithm, which facilitates writing the resulting causal statements (the QCA solution) as a Boolean expression of these terms. In accordance with Ragin and Davey (2014), our model shows that the pathways presented in Table 4 emerge as complex, parsimonious, and intermediate solutions. This result means that the model proposed is highly consistent. In this analysis, the pathways differed between management consulting companies performing their activity in non-IT fields (A) and management consulting companies performing their activity in IT (B). Noticeably, the existence of multiple configurations of causality for expected future changes in business models among management consulting companies indicates equifinality (Fiss 2011). 


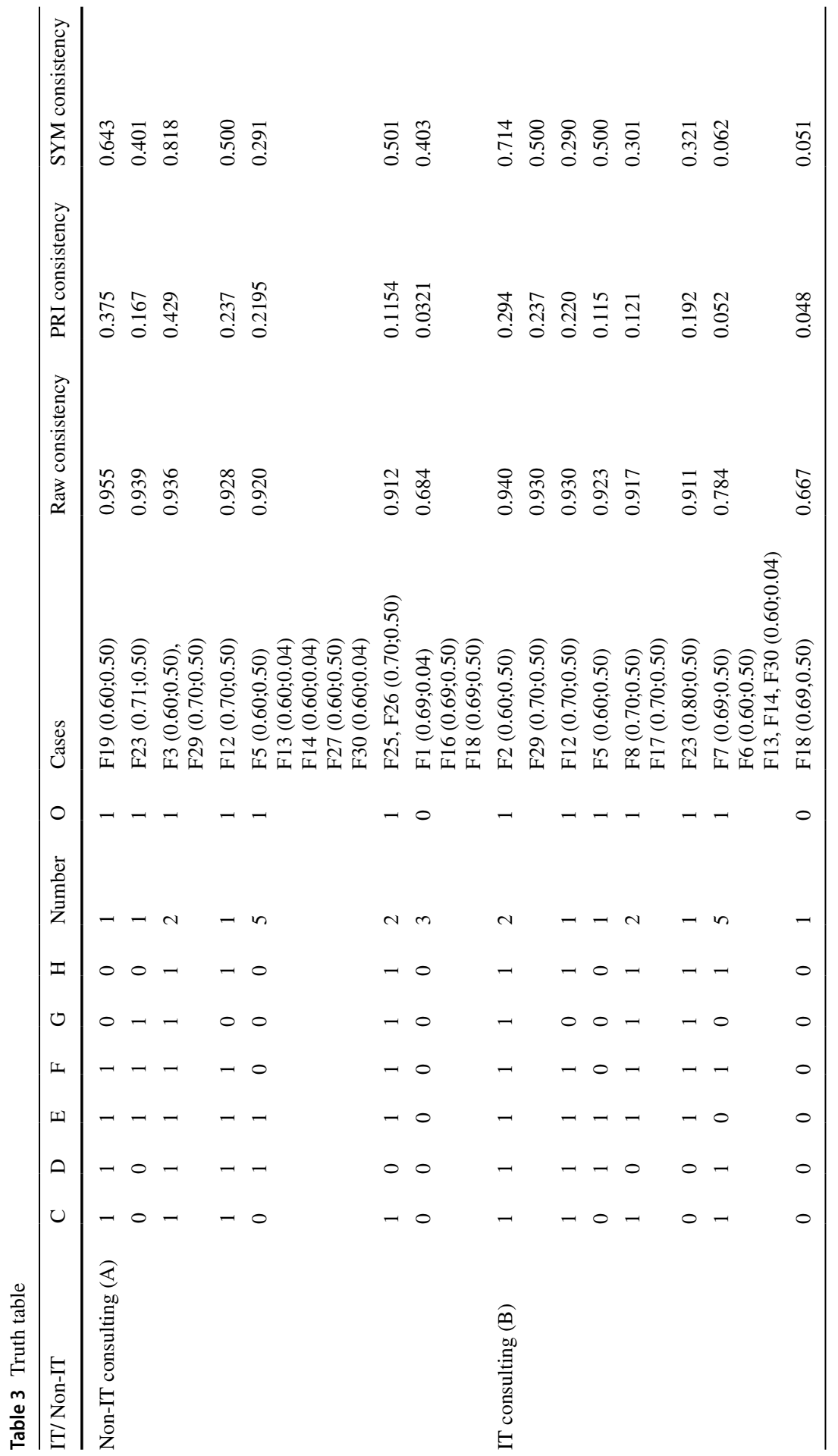


Table 4 Pathways to the outcome of interest

\begin{tabular}{|c|c|c|c|c|c|c|c|}
\hline Solution & $\begin{array}{l}\text { IT Pathway } \\
1\end{array}$ & $\begin{array}{l}\text { IT } \\
\text { Pathway } 2\end{array}$ & $\begin{array}{l}\sim \text { IT } \\
\text { Pathway } 3\end{array}$ & $\begin{array}{l}\text { Non-IT } \\
\text { Pathway } 4\end{array}$ & $\begin{array}{l}\text { Non-IT } \\
\text { Pathway } 5\end{array}$ & $\begin{array}{l}\sim \text { Non-IT } \\
\text { Pathway } 6\end{array}$ & $\begin{array}{l}\sim \text { Non-IT } \\
\text { Pathway } 7\end{array}$ \\
\hline $\begin{array}{l}\text { Consulting field: } \\
\text { Non-IT (A) }\end{array}$ & o & & & • & • & $\circ$ & $\circ$ \\
\hline $\begin{array}{l}\text { Consulting field: } \\
\text { IT (B) }\end{array}$ & $\cdot$ & $\cdot$ & 0 & & & & \\
\hline $\begin{array}{l}\text { Digital } \\
\text { transformation: } \\
\text { current business } \\
\text { model (C) }\end{array}$ & $\bullet$ & $\circ$ & $\bullet$ & $\bullet$ & • & $\circ$ & • \\
\hline $\begin{array}{l}\text { Internal triggers } \\
\text { (D) }\end{array}$ & $\bullet$ & • & • & - & • & • & - \\
\hline $\begin{array}{l}\text { External triggers } 1 \\
\text { (E) }\end{array}$ & • & $\cdot$ & $\circ$ & • & $\bullet$ & • & o \\
\hline $\begin{array}{l}\text { External triggers } 2 \\
\text { (F) }\end{array}$ & $\cdot$ & $\circ$ & $\circ$ & • & $\circ$ & $\bullet$ & $\circ$ \\
\hline $\begin{array}{l}\text { Digital } \\
\text { transformation } \\
\text { expected: } \\
\text { consultants' } \\
\text { competences }(\mathrm{G})\end{array}$ & $\circ$ & $\circ$ & o & $\circ$ & o & $\circ$ & $\circ$ \\
\hline $\begin{array}{l}\text { Digital } \\
\text { transformation } \\
\text { expected: new } \\
\text { services }(H)\end{array}$ & • & $\circ$ & $\circ$ & • & $\circ$ & $\circ$ & $\circ$ \\
\hline Raw coverage & 0.303 & 0.297 & 0.221 & 0.406 & 0.271 & 0.232 & 0.236 \\
\hline Unique coverage & 0.007 & 0.042 & 0.015 & 0.016 & 0.037 & 0.024 & 0.015 \\
\hline Raw consistency & 0.926 & 0.927 & 0.920 & 0.904 & 0.920 & 0.955 & \\
\hline $\begin{array}{l}\text { Overall solution } \\
\text { coverage }\end{array}$ & 0.890 & & & 0.910 & & & \\
\hline $\begin{array}{l}\text { Overall solution } \\
\text { consistency }\end{array}$ & 0.810 & & & 0.901 & & & \\
\hline
\end{tabular}

- Indicates the presence of a condition. $\bigcirc$ Indicates the absence of a condition. The gray areas indicate core conditions

Source: Based on Fiss (2011)

For the analysis, we used SPSS 13.0, Statistica 5.0, and Fuzzy-Set Qualitative Comparative Analysis (fsQCA) 3.0 software.

\section{Results}

The results of the fsQCA are presented in Table 4. Each column represents an alternative combination of conditions that are associated with the outcome, in this case, high expectations about future changes in their business model due to digital transformation. The gray cells are necessary or core conditions for each pathway. 


\subsection{Pathways for IT management consulting companies}

The overall solution representing the first three pathways that refer to IT management consulting companies has an acceptable overall consistency value of 0.89 (higher than the 0.75 threshold) and denotes the high extent to which cases correspond to this set-theoretic relationship (Fiss 2011). Raw consistency values are above the 0.75 threshold, denoting the degree to which configurations are subset of the outcome (Ragin 2009). Overall solution coverage shows that Pathways 1, 2 , and 3 jointly explain $89 \%$ of membership in the present outcome. Raw and unique coverage inform the extent to which the outcome is explained by each pathway (Ragin 2009), raw coverage considers the proportion of membership by each condition in the outcome, and unique coverage uses the proportion of cases that follow the specific configuration leading to the outcome (Ragin 2009) Unique coverage in this case means that Pathway 2 is more significant than Pathways 3 and 1 in terms of frequency of occurrence of the outcome, 0.042 against 0.015 and 0.007 , respectively. Considering raw coverage, the conditions explain the configurations at $30.30 \%$ for Pathway 1, 29.70\% for Pathway 2, and at $22.10 \%$ for Pathway 3.

Pathway 1 refers to three management consulting companies with expectations concerning business model changes due to digital transformation, characterized by:

- Context: their customers accept consulting practices based on IT (second external triggers category is a core condition according to Table 2, while the first external triggers category is also observed for these companies), and the internal triggers to become a more competitive MCC are also recognized.

- Current state of digital transformation: high inclusion of digital transformation in their current business model.

- Other expectations: high expectations for introducing new services based on digital transformation.

This pathway suggests that companies in this category are already at an advanced level of digital transformation, it is part of their current business model, they acknowledge both internal and external determinants of digital transformation, and they estimate both changes in their future business model associated with digital transformation, and the introduction of new services based on digital transformation.

Pathway 2 refers to seven companies with expectations about business model changes due to digital transformation, characterized by:

- Context: their customers accept only partially consulting practices based on IT (first external triggers category-a core condition), and the internal triggers for becoming a more competitive MCC are recognized.

- Current state of digital transformation: low inclusion of digital transformation in their current business model.

- Other expectations: low expectations for introducing new services based on digital transformation. 
This pathway suggests that companies in this category do not use digital transformation in their current business model, but based on observing customer acceptance of new services based on IT and the need to increase internal performance, they decided to include digital transformation as part of their future business model, though they do not expect to launch new services based on digital transformation.

Pathway 3 refers to two companies without expectations about business model changes due to digital transformation, characterized by:

- Context: their customers are not interested into consulting practices based on IT, but they recognize that they have internal triggers for becoming a more competitive company.

- Current state of digital transformation: high inclusion of digital transformation in their current business model.

- Other expectations: low expectations for introducing new services based on digital transformation.

This pathway suggests that management consulting companies in this category have already adopted IT in their current business model, they acknowledge only internal determinants of digital transformation, and in this way they estimate that their business model will not change in the future due to digital transformation.

\subsection{Pathways for Non-IT management consulting companies}

The overall solution representing the last four pathways (4-7), corresponding to non-IT management consulting companies, has an acceptable overall consistency value of 0.91, higher than 0.75 threshold (Fiss 2011). For all four configurations, the raw consistency values are also above the 0.75 acceptable threshold value (Ragin 2009). Overall solution coverage shows that Pathways 5-8 jointly explain $91 \%$ of membership in the present outcome. Unique coverage in this case shows that Pathway 5 is more significant than Pathways 6, 4, and 7. Considering the raw coverage, the conditions explain the configurations at $40.60 \%$ for Pathway $4,27.10 \%$ for Pathway 5, 23.20\% for Pathway 6, and 23.60\% for Pathway 7.

Pathway 4 refers to four companies with expectations about business model changes due to digital transformation, characterized by:

- Context: their customers accept both categories of consulting practices based on IT, with the internal triggers to become a more competitive company recognized as a core condition.

- Current state of digital transformation: high inclusion of digital transformation in their current business model.

- Other expectations: high expectations for introducing new services based on digital transformation.

This pathway suggests that management consulting companies in this category already have digital transformation as part of their current business model, they 
acknowledge both internal and external determinants of digital transformation, and in this way they estimate both changes in their future business model associated with digital transformation, and the introduction of new services based on digital transformation.

Pathway 5 refers to eight management consulting companies with expectations about business model changes due to digital transformation, characterized by:

- Context: their customers accept only partially consulting practices based on IT (first external triggers category), while the internal triggers for becoming a more competitive company are recognized as a core condition.

- Current state of digital transformation: high inclusion of digital transformation in their current business model.

- Other expectations: unrecognized expectations for introducing new services based on digital transformation.

This pathway suggests that companies in this category are already at an advanced level of digital transformation, but, based on observing customer acceptance of new services based on IT, they have low expectations about introducing new services based on digital transformation. However, their internal triggers for digital transformation are important, and they are strongly engaged in the digital transformation process.

Pathway 6 refers to four companies without expectations about business model changes due to digital transformation, characterized by:

- Context: their customers accept both categories concerning consulting practices based on IT, and the internal triggers to become a more competitive company are also recognized.

- Current state of digital transformation: low inclusion of digital transformation in their current business model.

- Other expectations: expectations about introducing new services based on digital transformation are not recognized.

This pathway suggests that management consulting companies in this category do not use digital transformation in their current business model, and they acknowledge both internal and external determinants of digital transformation, but they do not estimate any changes in their future business model due to digital transformation, and they do not expect any changes in their services based on digital transformation. It is surprising that management consulting companies in this category recognize internal and external triggers, but did not adopt or plan to adopt digital transformation in their future business model.

Pathway 7 refers to two management consulting companies and is identical to Pathway 3 for IT management consulting companies.

One interesting case is that of the variable expectations about consultants' competences $(\mathrm{G})$, which was not included as an important determinant of any of the pathways, denoting that the future changes expected related to digital 
transformation for management consulting companies' business model is not related to high expectations about the content of a consulting job.

A difference emerges between IT and non-IT management consulting companies with respect to the core variables that determine managers' expectations about business model changes due to digital transformation. The most important determinant for IT management consulting companies is related to external triggers. The acceptance by customers of the first category of consulting practices based on IT in the case of Pathway 1, and of the second category in the case of Pathway 2, are the main variables that determine high expectations concerning digital transformation influence on management consulting companies' business model. The expectations of non-IT Management consulting companies about the impact of digital transformation on their business model are driven by internal triggers, which are related more to internal effectiveness and efficiency.

\section{Discussion}

This research offers a new approach for studying management consulting companies' digital transformation by considering a more complex model that combines the context, previous digital transformation results, and managers' expectations about how digital transformation will affect their future business model. QCA is used for analysis, a method that can capture different paths to the same outcome (in this case, digital transformation expectations). The majority of the management consulting companies managers questioned anticipate a change and expect changes in the business model due to digital transformation, as estimated by Christensen et al. (2013). With regard to the dimension of the expected changes, only a few Romanian management consulting companies (Pathways 1 and 4) expect major changes because of a digital transformation that affects the current business model and the adoption of new services based on digital transformation. These findings confirm previous papers on management consulting companies' IT adoption, offering evidence on the low adoption of digital transformation practices in management consulting (Christensen et al. 2013).

In addition to the descriptive statistics and case studies previously used to analyze the digital transformation phenomenon (Allegra et al. 2000; Llewellyn 2017; Nissen et al. 2019), this study tests the contingency and management expectations theories on digital transformation. This paper operationalizes the digital transformation dynamic process in terms of configurations or paths using QCA (Ragin 2009), paths that explain the involvement of management consulting companies in digital transformation. Four paths $(1,2,4$, and 5) are for management consulting companies that expect digital transformation to affect their future business model. They arrive at this outcome in different ways. External triggers are the main determinants of this expectation (core condition) for IT management consulting companies (Pathways 1 and 2), whereas internal triggers are the core variables for the non-IT management consulting companies (Pathways 4 and 5). The influence of external triggers is proportional: stronger external triggers (recognition of both triggers categories) lead to expectations about the digital 
transformation impact on their business model related to the provision of new services based on IT (Pathways 1 and 4), but when fewer external triggers are recognized (category 1), the expectations only concern the impact of digital transformation on their current business. Internal triggers are recognized by all management consulting companies, but this variable is a core variable only for non-IT management consulting companies (Pathways 4 and 5). Three pathways $(3,6$, and 7$)$ are for management consulting companies that do not expect digital transformation to affect their future business model. In Pathways 3 and 7, managers believe that their current business model already includes digital transformation and that it has internal triggers, but they do not expect it to have any impact on their future model probably because of the lack of external triggers driving this to occur. Pathway 6 is for non-IT management consulting companies that recognize external triggers and the internal need for digital transformation, but they have not taken any steps in this direction (no digital transformation results yet).

By combining the results for positive and negative management consulting companies' expectations about the impact of digital transformation on their current business model, the theoretical model proves its effectiveness in explaining digital transformation. The way in which the context, digital transformation results, and expectations are associated is more complex than anticipated by simple models, which focus on parts of the model. Although previous digital transformation results are recognized as influencing future actions (Seifert and Nissen 2018; Chanias et al. 2019), we found that an inadequate external context (lack of customers' interest in services based on IT) could limit future digital transformation (Pathway 7). We also identified that an adequate external context (customers in IT industry) can trigger management consulting companies to start their digital transformation (Pathway 2) even in the absence of previous digital transformation results. The contingency dynamic nature of digital transformation is confirmed in this way, as the actions (in this case measured by expectations) are driven by a combination of previous digital transformation results and external context variables.

These pathways also explain how management consulting companies can achieve high levels of digital transformation by considering the digitalization-digital transformation (Verhoef et al. 2021) or digital technology-digital strategy paradigms (Zaki 2019). Although digital transformation is seen as a trigger for new entrants to create new business models (Nissen and Seifert 2018; Nissen et al. 2019), our results offer more insights, suggesting that management consulting companies that are fully involved in digital transformation (Pathways 1 and 4) are willing and able to launch new services or new business models because of their external triggers: the increased customer acceptance of IT-based consulting services. Those without increased external triggers (Pathway 5) are interested in improving their current business model, rather than creating new services and business models. In other words, some management consulting companies are improving their current business model (digitization or digital technology), whereas others are changing their business model (digital transformation or digital strategy). The combination of current digital transformation results, internal triggers, and strong external triggers lead to increased digital transformation expectations, as demonstrated by the expectation of launching new services based on digital transformation. The lack of external 
triggers or current digital transformation results are barriers to expecting future digital transformation impact at the business level.

\section{Conclusions}

The major contribution to the literature of this study is in explaining, based on QCA, how management consulting companies become involved in digital transformation. It provides evidence that managerial expectations of the digital transformation impact on the future business models of their companies, which are important determinants of future digital transformation strategies, are determined by a combination of the context and previous digital transformation results. We also provide evidence that adequate combinations of internal and external triggers and the existence of previous digital transformation activities and results can increase recognition of the importance of digital transformation in future business models and can lead to newer business services (digital strategy). Moreover, companies that do not have powerful external triggers can increase their internal efficiency-related triggers and target only improvements in existing business models because of technology adoption (technology strategy). A small number of management consulting companies do not expect digital transformation to have a great impact on their future business model, which might be related to the absence of external triggers and perhaps a lack of experience and previous digital transformation results that would push them in this new direction. Based on our analysis, Romanian management consulting companies have taken important steps toward digital transformation, but only a few expect digital transformation to drive business model changes or the creation of new services.

For practitioners, this study illustrates that digital evolution is a step-by-step transformation that affects individual components of management consulting companies' business model. First, the results highlight the importance of companies' understanding customers' needs if they are to change their current business model adequately for rising to the digital transformation challenge. Management consulting companies should analyze their market segments and observe customer habits related to technology adoption, as they need to understand the new technologies available and test them for their internal use. The existence of previous digital transformation results can affect the future digital transformation trajectory. Most of the management consulting companies questioned have already taken these steps. Second, management consulting companies need to reassess their business model. Only few of them have completely replaced their traditional services with those based on new digital approaches and technological innovations, in a total digital disruption. Most of the firms we analyzed anticipate a slower change in their business models, with traditional management consulting delivered with the use of IT. The potential for technology-based solutions is recognized, but these solutions may not create a long-term competitive advantage when other companies are reconsidering their entire business model with new services created from the perspective of digital transformation.

This study is the first exploration of the possible pathways in management consulting companies managers' expectations about digital transformation. Therefore, it 
has some limitations. First, we used a sample of Romanian management consulting companies. The market for consulting services might differ in Romania from that in other countries: in Romania, IT management consulting is a very important part of the industry because of the importance of the IT industry there. We hope these findings will encourage more in-depth research on management consulting companies business changes due to digital transformation in other countries and including other variables or using new methodologies. Qualitative approaches could be used to analyze the different perceptions and challenges faced by both consultants and customers. The COVID-19 crisis has driven many industries, including management consulting, to reexamine the potential for digital transformation-which, we emphasize, is not primarily about optimizing processes but, rather, about new business models and customer interface innovations.

Acknowledgements This work was supported by the grant TeMATIC-Art, Project co-financed by FEDR through Competitiveness Operational Programme 2014-2020, Funding contract: 14/01.09.2016.

\section{References}

Adner R, Helfat CE (2003) Corporate effects and dynamic managerial capabilities. Strateg Manag J 24(10):1011-1025

Allegra M et al (2000) Distance consulting for small and medium-sized enterprises. E-Business: Key Issues, Applications and Technologies. IOS Press, Amsterdam, pp 953-959

Bensberg F, Buscher G, Czarnecki C (2019) Digital transformation and IT topics in the consulting industry: a labor market perspective. Advances in Consulting Research. Springer, Berlin, pp 341-357

Berman SJ (2012) Digital transformation: opportunities to create new business models. Strateg Leadership 40(2):16-24

Beynon M et al (2020) Investigating total entrepreneurial activity and entrepreneurial intention in Africa regions using fuzzy-set qualitative comparative analysis (fsQCA). Small Enterp Res 27(2):146-164

Borup $\mathrm{M}$ et al (2006) The sociology of expectations in science and technology. Technol Anal Strateg Manag 18(3-4):285-298

Bronnenmayer M, Wirtz BW, Göttel V (2016) Success factors of management consulting. RMS 10(1):1-34

Cerruti C, Tavoletti E, Grieco C (2019) Management consulting: a review of fifty years of scholarly research. Manag Res Rev 42(8):902-925

Chanias S, Myers MD, Hess T (2019) Digital transformation strategy making in pre-digital organizations: The case of a financial services provider. J Strat Inf Syst 28(1):17-33

Christensen CM, Wang D, Van Bever D (2013) Consulting on the cusp of disruption. Harv Bus Rev 91(10):106-114

Cooper B, Glaesser J (2012) 'Qualitative work and the testing and development of theory: lessons from a study combining cross-case and within-case analysis via Ragin's QCA', in Forum: Qualitative Sozialforschung $=$ Forum: Qualitative Social Research $(\mathrm{p} 4)$. Freie Universität, Berlin

Curuksu JD (2018) Analysis of the management consulting industry. Data Driven. Springer, Berlin, pp $1-16$

Dacin TM, Goodstein J, Scott RW (2002) Institutional theory and institutional change: Introduction to the special research forum. Acad Manag J 45(1):45-56

Deelmann T (2018) Does digitization matter? Reflections on a possible transformation of the consulting business. Digital Transformation of the Consulting Industry. Springer, Berlin, pp 75-99

Drazin R, Van de Ven AH (1985) Alternative forms of fit in contingency theory. Adm Sci Q 30(4):514-539

Fan P, Urs N, Hamlin RE (2019) 'Rising innovative city-regions in a transitional economy: a case study of ICT industry in Cluj-Napoca Romania.' Technol Soc 58:101139 
Fiss PC (2011) Building better causal theories: A fuzzy set approach to typologies in organization research. Acad Manag J 54(2):393-420

Glückler J, Armbrüster T (2003) Bridging uncertainty in management consulting: The mechanisms of trust and networked reputation. Organ Stud 24(2):269-297

Gong C, Ribiere V (2020) Developing a unified definition of digital transformation. Technovation 102:102217

Greckhamer T et al (2013) Configurational Theory and Methods in Organizational Research. Emerald Group, Bingley UK

Greckhamer T et al (2018) Studying configurations with qualitative comparative analysis: Best practices in strategy and organization research. Strateg Organ 16(4):482-495

Greff, T. and Werth, D. (2016) 'Service digitization in the consulting domain À Classification and service implementation for a digital consulting front store pilot.' In Proceedings of the 5th International Conference on Serviceology: Short Papers and Posters, pp 115-122

Gresov C, Drazin R (1997) Equifinality: Functional equivalence in organization design. Acad Manag Rev 22(2):403-428

Gross A, Poor J, Roberson MT (2004) Management consulting in Central Europe. Consult Manag 15(1):33-38

Hanelt A et al (2020) A systematic review of the literature on digital transformation: insights and implications for strategy and organizational change. J Manage Stud. https://doi.org/10.1111/joms.12639

Hausberg JP et al (2019) Research streams on digital transformation from a holistic business perspective: a systematic literature review and citation network analysis. J Bus Econ 89(8-9):931-963

Helfat CE, Winter SG (2011) Untangling dynamic and operational capabilities: Strategy for the (N) everchanging world. Strateg Manag J 32(11):1243-1250

Laudien SM, Pesch R (2019) Understanding the influence of digitalization on service firm business model design: a qualitative-empirical analysis. RMS 13(3):575-587

Li F (2020) The digital transformation of business models in the creative industries: A holistic framework and emerging trends. Technovation 92:102012

Li L et al (2018) Digital transformation by SME entrepreneurs: A capability perspective. Inf Syst J 28(6):1129-1157

Llewellyn R (2017) How digital democratized consulting. Phantom Ex Machina. Springer, Berlin, pp 251-262

Mazareanu E (2020) Size of the management consulting market worldwide 2011-2020. https://www.stati sta.com/statistics/466460/global-management-consulting-market-size-by-sector/, Accessed September 2020 .

Meyer AD, Tsui AS, Hinings CR (1993) Configurational approaches to organizational analysis. Acad Manag J 36(6):1175-1195

Mosonyi S, Empson L, Gond J-P (2020) Management consulting: Towards an integrative framework of knowledge, identity, and power. Int J Manag Rev 22(2):120-149

Nissen V (2018) Digital transformation of the consulting industry-introduction and overview. Digital transformation of the consulting industry. Springer, Berlin, pp 1-58

Nissen V et al (2019) On the current state of digital transformation in the German market for business consulting. Advances in Consulting Research. Springer, Berlin, pp 317-339

Nissen V, Seifert H (2015) Virtualization of consulting: benefits, risks and a suggested decision process. In: Twenty-first Americas conference on information systems. Puerto Rico, pp 1-12

Nissen V, Seifert H (2018) Digital transformation in business consulting—status quo in Germany. Digital Transformation of the Consulting Industry. Springer, Berlin, pp 153-190

Ojala A (2016) Business models and opportunity creation: How IT entrepreneurs create and develop business models under uncertainty. Inf Syst J 26(5):451-476

Oliveira T, Martins MF (2011) Literature review of information technology adoption models at firm level. Electron J Inf Syst Evaluat 14(1):110-121

Overby E (2008) Process virtualization theory and the impact of information technology. Organ Sci $19(2): 277-291$

Pappas IO (2018) User experience in personalized online shopping: a fuzzy-set analysis. Eur J Mark 52(7/8):1679-1703

Parakala K (2015) Global consulting and IT service providers trends, an industry perspective. Technova, Australia

Ragin CC (2009) Redesigning Social Inquiry: Fuzzy Sets and Beyond. University of Chicago Press, Chicago 
Ragin CC (2014) The Comparative Method: Moving beyond Qualitative and Quantitative Strategies. University of California Press, Berkeley

Ragin CC and Davey S (2014) Fuzzy-set/qualitative comparative analysis 2.5. Irvine, CA: Department of Sociology, University of California.

Ragin CC, Strand SI, Rubinson C (2008) User's guide to fuzzy-set/qualitative comparative analysis. University of Arizona, Arizona

Schallmo D, Williams CA, Boardman L (2017) Digital transformation of business models—best practice, enablers, and roadmap. Int J Innov Manag 21(08):1740014

Schneider CQ, Wagemann C (2012) Set-Theoretic Methods for the Social Sciences: A Guide to Qualitative Comparative Analysis. Cambridge University Press, Cambridge

Seifert H, Nissen V (2018) Virtualization of consulting services: state of research on digital transformation in consulting and future research demand. Digital Transformation of the Consulting Industry. Springer, Berlin, pp 61-73

Swanson EB, Ramiller NC (1997) The organizing vision in information systems innovation. Organ Sci $8(5): 458-474$

Tornatzky LG, Fleischer M, Chakrabarti AK (1990) Processes of Technological Innovation. Lexington Books, USA

Türkeș MC et al (2019) Drivers and barriers in using industry 4.0: a perspective of SMEs in Romania. Processes 7(3):153-173

Verhoef PC et al (2021) Digital transformation: A multidisciplinary reflection and research agenda. J Bus Res 122:889-901

Vial G (2019) Understanding digital transformation: A review and a research agenda. J Strat Inf Syst 28(2):118-144

Wallin AJ, Fuglsang L (2017) Service innovations breaking institutionalized rules of health care. J Serv Manag 28(5):972-997

Yoruk E, Jones P (2020) Firm-environment alignment of entrepreneurial opportunity exploitation in technology-based ventures: a configurational approach. J Small Bus Manage. https://doi.org/10.1080/ 00472778.2020 .1800354

Zaki M (2019) Digital transformation: harnessing digital technologies for the next generation of services. J Serv Mark 33(4):429-435

Publisher's Note Springer Nature remains neutral with regard to jurisdictional claims in published maps and institutional affiliations.

Springer Nature or its licensor (e.g. a society or other partner) holds exclusive rights to this article under a publishing agreement with the author(s) or other rightsholder(s); author self-archiving of the accepted manuscript version of this article is solely governed by the terms of such publishing agreement and applicable law. 